\title{
REVIEW
}

\section{Papillary Thyroid Cancer-Aggressive Variants and Impact on Management: A Narrative Review}

\author{
Andrés Coca-Pelaz (D) · Jatin P. Shah · Juan C. Hernandez-Prera • Ronald A. Ghossein • \\ Juan P. Rodrigo · Dana M. Hartl · Kerry D. Olsen · Ashok R. Shaha · Mark Zafereo • \\ Carlos Suarez · Iain J. Nixon · Gregory W. Randolph • Antti A. Mäkitie · Luiz P. Kowalski • \\ Vincent Vander Poorten · Alvaro Sanabria • Orlando Guntinas-Lichius • Ricard Simo • \\ Peter Zbären · Peter Angelos · Avi Khafif · Alessandra Rinaldo · Alfio Ferlito
}

Received: April 28, 2020 / Published online: June 1, 2020

(C) The Author(s) 2020

\section{ABSTRACT}

Introduction: Aggressive variants of papillary thyroid cancer (PTC) have been described with increasing frequency. These variants include diffuse sclerosing variant, tall cell variant,

This article was written by members and invitees of the International Head and Neck Scientific Group (https:// www.IHNSG.com).

Digital Features To view digital features for this article go to https://doi.org/10.6084/m9.figshare.12302081.

A. Coca-Pelaz $(\varangle) \cdot$ J. P. Rodrigo

Department of Otolaryngology, Hospital

Universitario Central de Asturias-University of

Oviedo, Oviedo, Asturias, Spain

e-mail: acocapelaz@yahoo.es

J. P. Shah · A. R. Shaha

Head and Neck Service, Department of Surgery,

Memorial Sloan Kettering Cancer Center, New York,

NY, USA

J. C. Hernandez-Prera

Department of Pathology, Moffitt Cancer Center,

Tampa, FL, USA

R. A. Ghossein

Department of Pathology, Memorial Sloan Kettering

Cancer Center, New York, NY, USA

D. M. Hartl

Division of Surgical Oncology, Gustave Roussy

Cancer Center and Paris-Sud University, Villejuif

Cedex, Paris, France columnar cell variant, solid variant, and hobnail variant.

Methods: We have performed a review of the more aggressive variants of PTC with respect to main characteristics, histological and molecular features, and the consequences that the knowledge of these variants should have in the treatment of the patients.

Results: At the present time, we do not know the prognostic value of these aggressive PTC variants. The extent of the surgical treatment and adjuvant therapy necessary should be decided on the basis of the extent of the tumor

\section{K. D. Olsen}

Department of Otorhinolaryngology, Mayo Clinic, Rochester, MN, USA

M. Zafereo

Division of Surgery, Department of Head and Neck Surgery, The University of Texas MD Anderson Cancer Center, Houston, TX, USA

A. Coca-Pelaz · J. P. Rodrigo · C. Suarez Instituto de Investigación Sanitaria del Principado de Asturias, IUOPA, CIBERONC, Oviedo, Asturias, Spain

\section{J. Nixon}

Department of Surgery and Otolaryngology, Head and Neck Surgery, Edinburgh University, Edinburgh, Scotland, UK

G. W. Randolph

Massachusetts Eye and Ear Infirmary, Massachusetts General Hospital, Harvard Medical School, Boston, MA, USA 
at presentation and the opinion of experienced clinicians.

Conclusion: These aggressive variants should be known by clinicians, to avoid underdiagnosis, and treated according to the latest recommendations in the literature.

Keywords: Aggressive variants papillary thyroid cancer; Columnar cell variant; Diffuse sclerosis variant; Hobnail variant; Solid variant; Tall cell variant

\section{Key Summary Points}

There are a small group of tumors among papillary thyroid cancers with a more aggressive behavior, higher rates of recurrence, and metastasis.

Achieving a correct histological diagnosis of these variants is essential for the prognosis of patients.

Knowing the clinical characteristics of these tumors can help us suspect their presence, given the different clinical signs of aggressiveness they show.

\section{A. A. Mäkitie}

Department of Otorhinolaryngology, Head and Neck Surgery, University of Helsinki and Helsinki University Hospital, Helsinki, Finland

\section{P. Kowalski}

Head and Neck Surgery and Otorhinolaryngology Department, A C Camargo Cancer Center, São Paulo, Brazil

\section{Vander Poorten}

Section Head and Neck Oncology,

Otorhinolaryngology-Head and Neck Surgery and Department of Oncology, University Hospitals Leuven, KU Leuven, Louvain, Belgium

\section{A. Sanabria}

Department of Surgery, School of Medicine, Universidad de Antioquia/Hospital Universitario San Vicente Fundación-CEXCA Centro de Excelencia en Enfermedades de Cabeza y Cuello, Medellín, Colombia

O. Guntinas-Lichius

Department of Otorhinolaryngology, Institute of Phoniatry/Pedaudiology, Jena University Hospital, Jena, Germany
After the diagnosis it is important to carry out a more aggressive treatment than in the classic variants.

Each patient must be evaluated individually in order to provide the appropriate surgical treatment as well as a complementary treatment trying to improve their prognosis.

\section{INTRODUCTION}

Papillary thyroid carcinoma (PTC) is the most common endocrine malignancy [1]. It represents approximately $85 \%$ of all follicular derived well-differentiated thyroid cancers. With a 10-year survival of approximately 93\%, it is considered an indolent tumor [2]. Despite the fact that the majority of PTCs are well differentiated with a low rate of local invasion, recurrences, or metastases (regional or distant), there are a small group of tumors which show heterogeneity with more aggressive variants, with distinct clinical, pathological, and

\section{R. Simo}

Head and Neck Cancer Unit, Guy's and St Thomas' Hospital NHS Foundation Trust London, London, UK

\section{P. Zbären}

Department of Otorhinolaryngology-Head and Neck Surgery, University Hospital, Berne, Switzerland

\section{P. Angelos}

Department of Surgery, University of Chicago Medical Center, Chicago, IL, USA

\section{A. Khafif}

Head and Neck Surgery and Oncology Unit, A.R.M. Center for Advanced Otolaryngology Head and Neck Surgery, Assuta Medical Center, Tel Aviv, Israel
A. Rinaldo
University of Udine School of Medicine, Udine, Italy
A. Ferlito
Coordinator of the International Head and Neck
Scientific Group, Padua, Italy 
molecular features. These pathological subtypes are considered in the latest American Thyroid Association (ATA) guidelines as conferring an intermediate risk of recurrence [3]. Among the most aggressive variants of PTC are the diffuse sclerosing variant (DSV), tall cell variant (TCV), columnar cell variant (CCV), solid variant (SV), and hobnail variant (HV). These variants have been associated with higher rates of recurrence and metastasis, as well as in some cases absence of avidity to radioiodine (RAI) therapy and may have lower survival rate [4]. Given the lack of knowledge of the natural history of these more aggressive variants, the treatment of these patients is often inadequate or suboptimal. The aim of this review is to describe the aggressive variants of PTC, emphasizing their differential histological and molecular characteristics (Table 1), their clinical manifestations, biological behavior, and the implications these variants have on selection of treatment and prognosis.

This article is based on previously conducted studies and does not contain any studies with human participants or animals performed by any of the authors.

\section{AGGRESSIVE VARIANTS OF PTC}

\section{Diffuse Sclerosing Variant}

\section{Main Features}

DSV accounts for almost $6 \%$ of all PTCs [5]. It was reported as a variant of PTC by Vickery et al. in 1985 [6]. This lesion often presents as a diffuse enlargement of the thyroid gland usually without forming a dominant nodular lesion [1]. When compared with classic PTC, DSV has unique clinical features, including a higher prevalence of underlying Hashimoto's thyroiditis, higher female-to-male ratio, and younger age [7]. In the report by Pillai et al. [8], after reviewing 25 studies with 641 patients affected by a DSV, they found that it is most often seen in the third decade of life with a mean age at presentation of 30 years (median 28 , range 6-78 years). Eighty-one percent were female and $19 \%$ were male, with a female-tomale ratio of 4.3:1. On the other hand, there are studies in which the age of onset is higher, around 40 years or older [9-11].

In the study by Fridman et al. [12] in 2012, this variant of PTC was most often seen after exposure to high levels of radiation (such as the Chernobyl accident). This was also reported in the study by Nikiforov and Gnepp [13] where $10 \%$ of pediatric PTCs after that accident were DSV. DSV appears to be more aggressive than classic PTC and shows at presentation a high frequency of cervical and pulmonary metastases $[10,14]$. Despite this aggressive behavior, the overall disease-specific survival rate was similar to the classic type. This was demonstrated in the study by Lam and Lo [9] after a median followup period of 10.7 years. The overall diseasespecific survival rate was $93 \%$, similar to classic PTC. Furthermore, in the aforementioned study by Pillai et al. [8] cancer recurrence and cancerrelated mortality were reported in $14 \%$ and $3 \%$, respectively, whereas distant metastases were noted in approximately $5 \%$ of the cases. In 2012, Kazaure et al. [11] published a retrospective review of the Surveillance, Epidemiology, and End Results (SEER) database from 1988 to 2008 including 261 patients with DSV, 573 with TCV, and 42,904 with PTC. They reported a 20-year increase in the incidence of classic PTC of $60.8 \%$, while DSV and TCV incidence increased by $126 \%$ and $158 \%$, respectively. These aggressive variants were associated with higher rates of extrathyroid extension, multifocality, and nodal (DSV $72.2 \%$ vs. $66.8 \% \mathrm{TCV}$ vs. $56.3 \%$ PTC, $P<0.001)$ and distant metastases (TCV $11.1 \%$ vs. $7.3 \%$ DSV vs. $4.3 \%$ PTC, $P<0.001)$ compared to classic PTC. In this study, survival was decreased in both aggressive variants, but the difference was greater for TCV (5-year overall survival $87.5 \%$ DSV, $80.6 \%$ TCV vs. $93.5 \%$ PTC, $P<0.001)$. Thyroid surgery and RAI therapy were independently associated with improved overall survival. In a systematic review of DSV, Vuong et al. [15] identified 732 cases of DSV in 16 articles. They found that DSV manifested more aggressive clinicopathological behavior than classic PTC such as higher rate of vascular invasion (odds ratio [OR] 5.33; 95\% CI 3.08-9.23), extrathyroid extension (OR 2.96; 95\% CI 2.04-4.30), lymph node metastasis (OR 5.40; 95\% CI 2.82-10.35), and distant 
Table 1 Main histological characteristics of the aggressive variants of PTC

\begin{tabular}{|c|c|c|c|}
\hline Variant & Clinical features & Histology & Molecular \\
\hline \multirow[t]{7}{*}{ DSV } & Diffuse enlargement & Diffuse involvement of one or both lobes & RET/PTC1 \\
\hline & ETE & Micropapillary tumor clusters in cleft-like spaces & RET/PTC3 \\
\hline & Associated Hashimoto's thyroiditis & consistent with lymphatics & $B R A F^{\mathrm{V} 600 \mathrm{E}}$ \\
\hline & \multirow{4}{*}{ 2nd-3rd decade of life } & Squamous metaplasia & mutations \\
\hline & & Numerous psammoma bodies & $(50-61 \%)$ \\
\hline & & Extensive lymphocytic infiltration of tumor & \\
\hline & & Marked tumor fibrosis & \\
\hline \multirow[t]{3}{*}{ TCV } & Large tumor size & $\geq 30 \%$ tall cells (height twice their width) with & $B R A F$ mutations \\
\hline & ETE & oncocytic cytoplasm & $(80-100 \%)$ \\
\hline & 5th-6th decade of life & Elongated follicles & \\
\hline \multirow[t]{6}{*}{$\mathrm{CCV}$} & $\begin{array}{l}\text { Infiltrative form with extrathyroid } \\
\text { extension: rapid growth rate }\end{array}$ & $\begin{array}{l}\text { Columnar cells with pseudostratified nuclei and } \\
\text { no eosinophilic cytoplasm }\end{array}$ & $B R A F^{\mathrm{V} 600 \mathrm{E}}(33 \%)$ \\
\hline & Local invasion & Hypercellular neoplasm with thin papillae and & \\
\hline & Early lymph node metastasis & glandular structures & \\
\hline & High rate of recurrences & Nuclear features of papillary carcinoma not as & \\
\hline & 5th-6th decade of life & well developed as classic PTC & \\
\hline & $\begin{array}{l}\text { Encapsulated form minimally invasive: } \\
\text { high cure rate }\end{array}$ & $\begin{array}{l}\text { Occasional subnuclear vacuolization or even } \\
\text { clear cytoplasm }\end{array}$ & \\
\hline \multirow[t]{4}{*}{ SV } & 5th decade of life & Solid nested growth pattern & RET/PTC3 \\
\hline & Large tumor size & Well-developed nuclear features of PTC & $B R A F$ mutation \\
\hline & ETE & Lack of tumor necrosis & \\
\hline & Higher risk of metastasis & Absence of marked mitotic activity & \\
\hline \multirow[t]{4}{*}{$\mathrm{HV}$} & 6th decade of life & $\geq 30 \%$ of hobnail cells & $B R A F$ mutations \\
\hline & ETE & Micropapillary growth patterns & $(25 \%)$ \\
\hline & Lymph node metastasis & High nuclear/cytoplasmic ratio & $\begin{array}{l}\text { TP53 mutations } \\
(55 \%)\end{array}$ \\
\hline & & & $\begin{array}{l}\text { NOTCH1 } \\
\text { mutations }(5 \%)\end{array}$ \\
\hline
\end{tabular}

$D S V$ diffuse sclerosing variant, $T C V$ tall cell variant, $C C V$ columnar cell variant, $S V$ solid variant, $H V$ hobnail variant, $E T E$ extrathyroidal extension

metastasis (OR 3.61; 95\% CI 1.89-6.88). DSVs were more likely to relapse (OR 2.83; 95\% CI 1.59-5.05) and were associated with a worse overall survival (hazard ratio [HR] 1.89; 95\% CI 1.36-2.62).

\section{Diagnosis}

Histological Features

The main histological characteristic is a diffuse involvement of one or both thyroid lobes with 
dense sclerosis, patchy to dense lymphocytic infiltrates, abundant psammoma bodies, extensive squamous metaplasia, and extensive lymphovascular invasion [1] (Fig. 1a, b). Takagi et al. [16] described the characteristics of DSV in fine needle aspiration (FNA) cytology as follows: solid cell balls and/or hollow balls containing lymphocytes; hobnail cells; septate cytoplasmic vacuoles; large unilocular vacuoles; squamous differentiation; abundant psammoma bodies; lymphocytic background; and the absence or relative lack of characteristic nuclear features of PTC. They reported that 17 out of 20 patients with DSV had Hashimoto's thyroiditis. The coexistence with Hashimoto's thyroiditis can make diagnosis of this tumor by FNA difficult [8]. It is important not to confuse the squamous metaplasia found in DSV with anaplastic carcinoma with squamous features. The lack of nuclear pleomorphism in the squamous nests and of course the young age of the patient should guide the pathologist toward a diagnosis of DSV.

Some authors such as Koo et al. [17] have studied different immunohistochemical characteristics that may define DSV. They found that immunohistochemical staining for $p 63$ was positive in $28.6 \%$ of cases with DSV in the squamous metaplasia, p53 was noted in $42.9 \%$ in the solid component, and Galectin-3 was not expressed in $16.3 \%$ of the cases. EMA was positive in $40.8 \%$.

\section{Molecular Features}

The molecular profile of DSV is variable; the common genetic alterations are rearranged during transfection/papillary thyroid carcinoma (RET/PTC) rearrangements (RET/PTC1 > RET/ PTC3) and BRAF $F^{V 600 E}$ mutations. RET/PTC3 alterations are seen in patients who present at an advanced disease stage and who have a poor clinical outcome $[18,19]$. In 2016, Joung et al. [20] investigated the genetic alterations of DSV. They found RET/PTC rearrangements as the major molecular alteration which was associated with an advanced stage at diagnosis and a poor clinical outcome. RET/PTC rearrangements are commonly seen in pediatric PTCs, so the high incidence of this molecular finding in DSV might be a matter of age of the patients, the same as the overall good survival despite the aggressive clinical presentation. $B R A F$ mutation has also been observed in DSV, but at lower frequency than in PTC $[21,22]$. However, the reported rates of $B R A F$ mutation vary significantly between studies. Lee et al. [23] reported $B R A F$ mutation in $50 \%$ of DSV cases, while classic PTC showed a $62 \%$ positivity rate. Lim et al. [24] confirmed these results although with somewhat different percentages (DSV 61\%, PTC 75\%). Asioli et al. [25], Koperek et al. [26], and Sheu et al. [27] reported comparable results although with percentages of even $0 \%$ in DSV specimens. To conclude, DSV has different pathological and molecular profiles when compared to conventional PTC.

\section{Tall Cell Variant}

\section{Main Features}

The TCV was first described by Hawk and Hazard in 1976 [28]; however, the descriptions of PTC with tall cell morphology in the literature date back to 1948 [29]. Among PTCs they found a group of tumors with "a distinctive columnar cell shape with the height of the cell being at least twice the breadth". The World Health Organization (WHO) [1] defines TCV as a tumor that is composed "of cells that are two to three times as tall as they are wide, and that show abundant eosinophilic (oncocytic-like) cytoplasm. Because tall-cell areas are frequently present in otherwise conventional papillary carcinomas, tall cells must account for $\geq 30 \%$ of all tumor cells for the diagnosis of the tall-cell variant". This definition varies from the 2004 WHO Classification which defines TCV as a tumor "composed predominantly" of neoplastic cells with a 3:1 height to with ratio. The percentage of tall cells needed to make a TCV diagnosis varies between the studies: Ganly et al. [30] recommend at least 30\%, Beninato et al. [31], and Oh et al. [32] suggested that when the tumor is composed of more than 10\% tall cells, it is an aggressive variant. Some expert histopathologists such as LiVolsi [33] recommend that a focus of tall cells be mentioned in the pathology report, regardless of the percentage. These findings should encourage the managing clinician to monitor the patient 


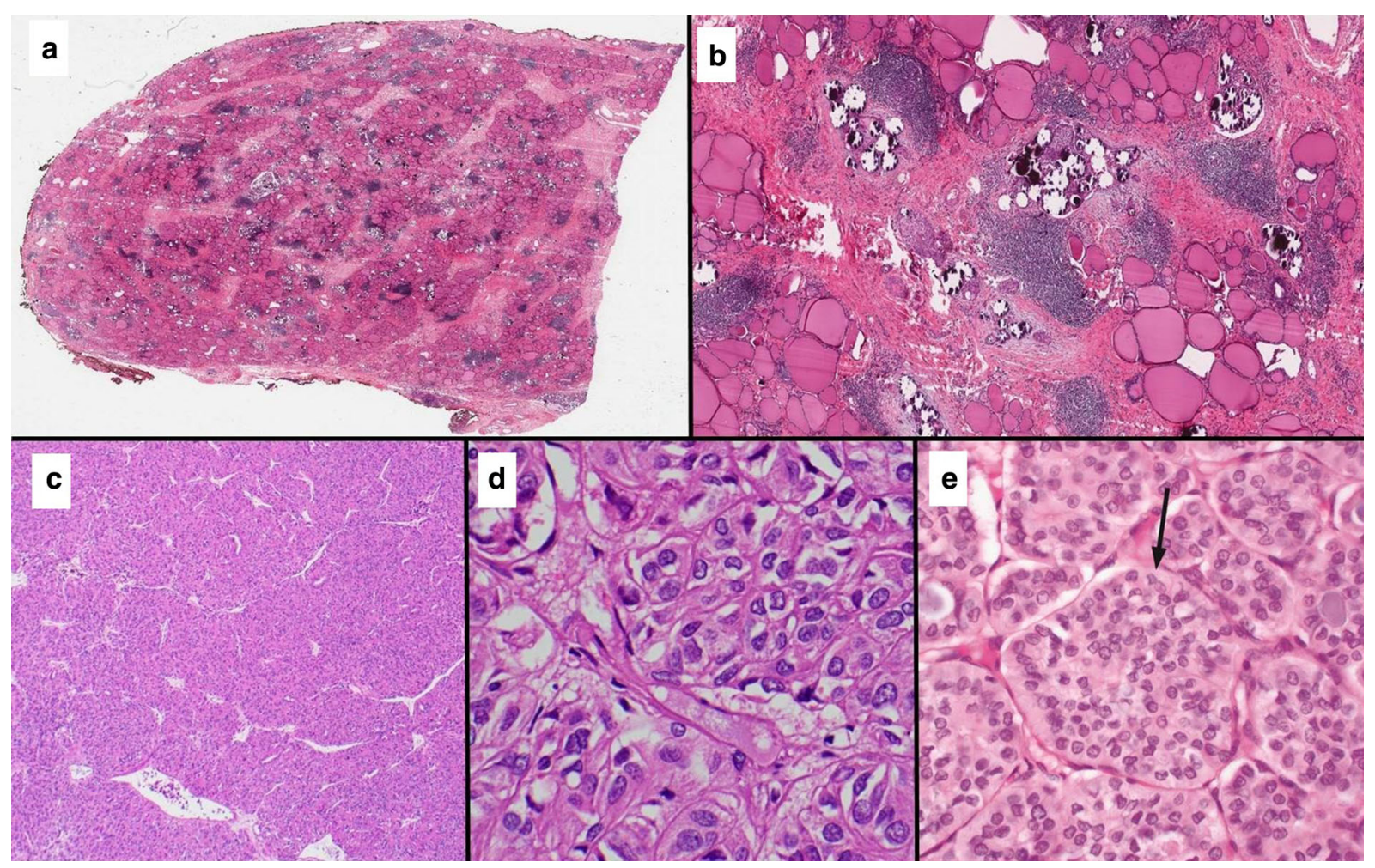

Fig. 1 a Scanning view of thyroidectomy specimen affected with DSV of PTC classically showing the lack of mass-forming lesion. b Low power microscopic view $(4 \times 10)$ of DSV showing numerous psammoma bodies and tumor cells infiltrating throughout the thyroid parenchyma associated with fibrosis and chronic lymphocytic thyroiditis. c Low power microscopic view $(4 \times 10)$ of SV of PTC showing a trabecular and nested growth. d High power microscopic view $(40 \times 10)$ of SV showing

closely after treatment, given the greater aggressiveness of these tumors.

Wang et al. [34] noticed that TCV is more frequent in women, with a female to male ratio of approximately 2.9:1. In 2017, Gunalp et al. reported 3128 well-differentiated thyroid carcinomas, including $56 \mathrm{TCV}, 66 \%$ of which occurred in women. In their study, TCV represents approximately $1-19 \%$ of PTC, usually in older patients and are often large in size at diagnosis [35]. Kazaure et al. [11] reported that the incidence of TCV had increased by $158 \%$ over 20 years. The average age of patients with TCV is usually higher than that of patients with PTC, and ranges from 41 to 66 years $[11,34,36]$. TCV is associated with a higher recurrence rate diagnostic nuclear features of papillary thyroid carcinoma, including nuclear enlargement, chromatin clearing, overlapping, irregular nuclear membranes and grooves in the absence of diagnostic criteria for poorly differentiated thyroid carcinoma. e High power microscopic view of a solid variant of papillary thyroid carcinoma occurring in a 10-year-old Ukrainian boy exposed to the Chernobyl disaster. The tumor is composed of solid/nests (arrow)

and shorter survival than classic PTC. This may be because it occurs in older patients, presents with larger tumor size, and more frequent extrathyroidal involvement. Even when the authors corrected for some factors like age, gender, and tumor size, this variant still remained more aggressive than classic PTC [37]. In contrast, Ganly et al. [30] observed in multivariate analysis that the presence of more than five positive nodes and extranodal extension were the only independent prognostic factors of neck and distant recurrence-free survival raising the issue of whether tall cell variant is more aggressive than classic PTC when stratified by stage. Russo et al. [38] found that TCV and classic PTC had similar outcome when treated 
similarly with total thyroidectomy and RAI. In a recent meta-analysis, Vuong et al. [39] found that even PTCs with only $10 \%$ tall cells were associated with a poor clinical outcome. They suggest that the presence of tall cells in a small percentage, even only $10 \%$, must be reported. Bongers et al. [40] studied the proportion of tall cells needed to influence prognosis in a series of 96 PTCs with focal tall cell change, 35 with the TCV histology, and 104 control cases. Factors associated with poor clinical prognosis were significantly more common in those with focal tall cell change and TCV. Five-year disease-free survival was higher for the control group (92.7\%, CI 87.4-98.0) compared with focal tall cell change $(76.3 \%$, CI 66.1-86.5) and the TCV histology (62.2\%, CI 43.2-81.2). When stratified in groups consisting of tall cell proportions $(<10 \%, 10-19 \%, 20-29 \%$, and $\geq 30 \%)$, identification of at least $10 \%$ tall cell change was associated with worse outcome $(P=0.002)$. In contrast, Wong et al. [41] reported that only tumors with greater than $50 \%$ of tall cell component had a more aggressive behavior. Thus, the proportion of tall cell component that is clinically relevant is still a matter of debate. In addition, it is important to highlight that there is significant subjectivity and lack of agreement in the identification and reporting of TCV of PTC among pathologists [42]. Likewise, the reported percent of a given tumor composed of tall cells is a visual estimate contingent on tissue sampling. On the basis of the above data, it is still unclear whether stage for stage tall cell variant is more aggressive than classic PTC.

\section{Diagnosis}

\section{Histological Features}

In addition to being defined by the presence of a significant proportion of tall cells as described above, tall cell variant PTC exhibits stretched elongated follicles in histologic sections (Fig. 2a, b). This finding also termed "tram-track appearance" is quite characteristic of this variant and should prompt a search for tall cells when detected at low magnification. Although most TCVs PTC are not encapsulated, rarely one can encounter an encapsulated tumor even a non-invasive encapsulated TCV. Other histological diagnostic criteria of TCV include eosinophilic cytoplasm, distinct cell borders, and prominent/exaggerated nuclear features of PTC. These features have not received enough attention in the literature, and it is important to recognize that the diagnosis TCV is not limited to a specific height to width ratio and percentage criteria. Several studies have tried to define the cytologic features that differentiate TCV from classic PTC on FNA. TCV is characterized by elongated tall cells with oncocytic cytoplasm, distinct cell borders, different intranuclear inclusions (compared with classic PTC), prominent central nucleoli, multiple inclusions within the same nucleus imparting a "soap bubble appearance", and higher frequency of cases with lymphocytic infiltration [43, 44].

\section{Molecular Features}

As with PTC, the role of the $B R A F^{V 600 E}$ mutation in TCV has been investigated. It has been observed that its prevalence in TCV is between $80 \%$ and $100 \%$. Wong et al. [41] found that the higher frequency of $B R A F$ mutations was found in cases with greater than $50 \%$ of tall cell component, and that these cases frequently have a pathogenic secondary mutation (usually in the $T E R T$ promoter gene). RET/PTC rearrangements have also been studied, with RET/PTC3 described in $35.8 \%$ of TCV cases, compared with $17.2 \%$ in classic PTC $[32,45,46]$. Moreover, the Cancer Genome Atlas (TCGA) reported that cases of TCV cluster together at the mRNA level and were characterized by miR-21 expression [47]. These differences in the rate of driver mutations could be due to differences in the definition of TCV PTC.

\section{Columnar Cell Variant}

\section{Main Features}

The CCV of PTC is a rare subtype that accounts for $0.15-0.2 \%$ of all PTCs [48]. It is known to have a rapid growth rate, associated with local invasion and early development of lymph node metastasis, and has a high rate of recurrence [49]. This aggressive variant may not respond to RAI therapy [37]. CCVs are described in the WHO 


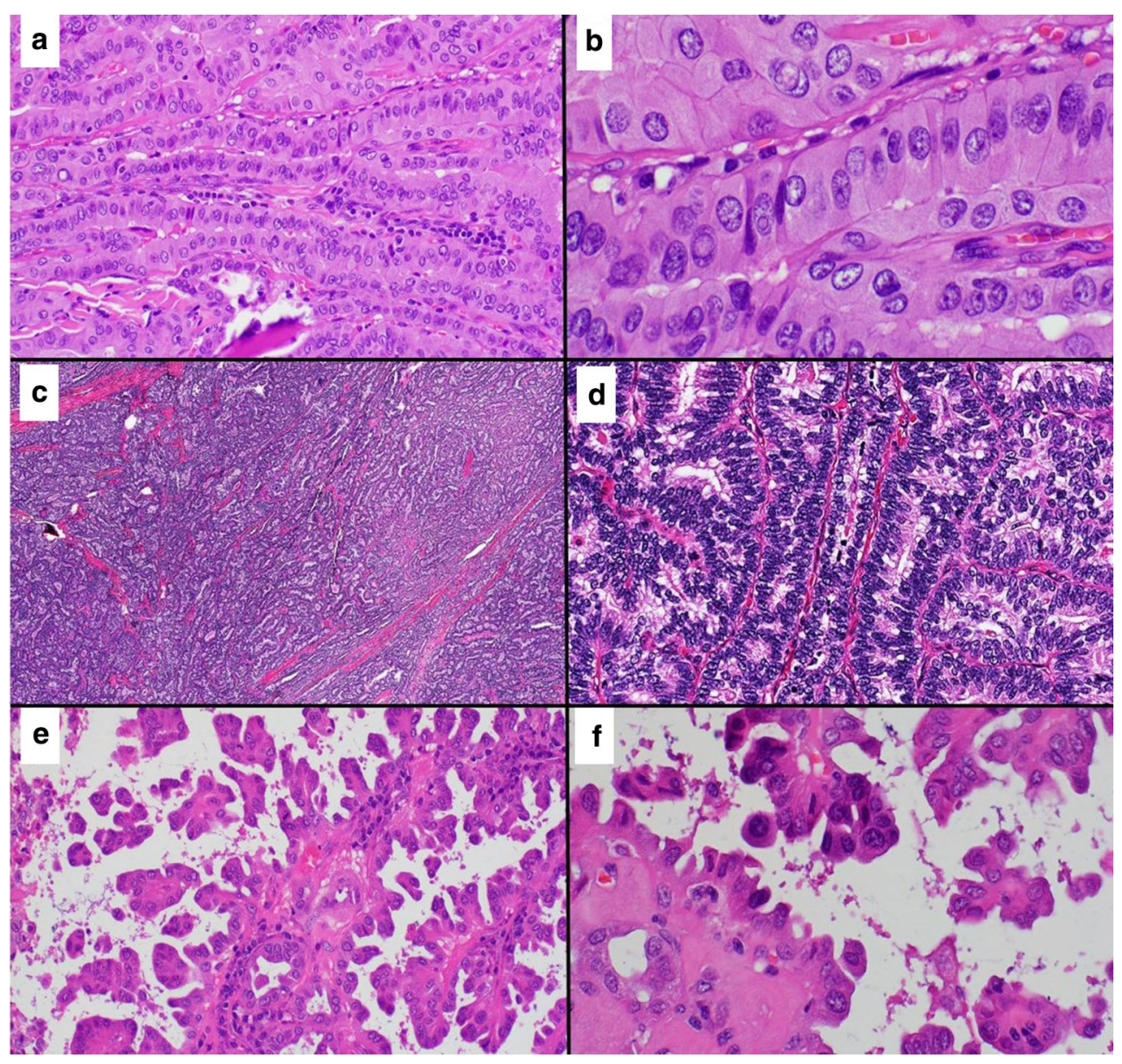

Fig. 2 a Medium magnification view $(20 \times 10)$ of a TCV of PTC showing elongated follicles with parallel arrangement ("tram-track" appearance). b High magnification view $(60 \times 10)$ of TCV exhibiting tumor cells that are taller than wider (2:1 or $3: 1$ height to width ratio) with moderate to abundant light eosinophilic cytoplasm, distinct cell borders, and prominent nuclear features diagnostic of PTC. c Low power microscopic view $(4 \times 10)$ of CCV of PTC showing a highly cellular neoplastic proliferation. d High magnification view

classification as "typically hypercellular neoplasms showing thin papillae or glandular-like spaces lined by pseudostratified epithelium, which can also be seen on FNA. The neoplastic cells show occasional subnuclear vacuolization or even clear cytoplasm" [1]. The mitotic activity is elevated, with a Ki67 index of about a $20 \%$ or higher. CCV lesions are positive for TTF1, thyroglobulin, cyclin D1, bcl-2, membranous localization of $\beta$-catenin, and estrogen and progesterone expression regardless of the gender
$(40 \times 10)$ of $\mathrm{CCV}$ exhibiting elongated tumor cells and hyperchromatic nuclei and prominent nuclear stratification, the cardinal feature of this variant. e Medium magnification view $(20 \times 10)$ of an HV of PTC showing complex papillary growth and micropapillary architecture. f High magnification view $(60 \times 10)$ of tumor cells with hobnail morphology characterized by pleomorphism, high nuclear to cytoplasmic ratio, apically or eccentrically placed nuclei, and surface bulging

of the patient, and occasionally can be positive for CDX2 (up to $55 \%$ of cases) [37, 50, 51]. CCVs can be encapsulated or present as an infiltrating mass. Often the most common finding is an asymptomatic or enlarging neck mass [52]. Cho et al. [53] in their study of six CCV cases (one male and five female) reported a median age of 34 years (mean 41.7). Chen et al. [54] describe nine cases (five male, four female) of $\mathrm{CCV}$, with a mean age of 57 years. Bongiovanni et al. published 11 specimens of FNA cytology (from three 
male and seven female patients, with a mean age of 49.4 years).

Wang et al. [55] and Jiang et al. [56] have both used the SEER database to demonstrate that CCV is associated with higher rates of extrathyroid extension, nodal and distant metastases, and poorer overall survival in comparison with classic PTC. Average survival in the study by Wang et al. was $44.06 \pm 33.01$ months compared to an average survival of $48.89 \pm 33.4$ months for classic PTC $(p<0.001)$, and the rates of cancer-specific mortality per 1000 person-years for CCV and PTC were 16.85 (95\% CI 13.11-21.65), and 2.51 (95\% CI 2.32-2.72), respectively. In the study by Jiang et al. [56], the 10-year overall survival was $89.02 \%$ (96.98\% in classic PTC; $p<0.0001)$. However, in the seminal study by Wenig et al. [52], the patients' tumors were divided into encapsulated with minimal invasion and widely infiltrative. The encapsulated tumors occurred mostly in young female patients while the infiltrative ones in older patients with an almost equal male to female ratio. The encapsulated minimally invasive $\mathrm{CCV}$ behaved in a very indolent fashion while the widely infiltrative tumors had a very poor outcome. This important study demonstrates that columnar cell variant when encapsulated and confined to the thyroid has an outcome similar to classic PTC. Although as a group CCV is more aggressive than classic PTC, it may not be true when these carcinomas are compared according to their invasive status. This has important implications for risk stratification and therefore therapy.

\section{Diagnosis}

\section{Histological Features}

The CCV is histologically defined by the presence of a significant amount of columnar cells displaying pseudostratified nuclei (Fig. 2c, d). The nuclear features of papillary carcinoma are not as well developed as in classic PTC or TCV PTC. The morphological appearance of CVV can mimic adenocarcinomas of the gastrointestinal tract and endometrium. There is no consensus as far as the percentage of columnar cells required for that diagnosis. Indeed, the proportion required according to different authors ranges from 30\% to $80 \%[52,57]$. According to Bongiovanni et al. [57] there are several cytomorphologic features that are common in all FNAs from CCV tumors: high cellularity, papillae, medium or large cell size, single cells, and pseudostratified nuclei (nuclear crowding). There are other characteristics seen in more than $50 \%$ of the cases: colloid, elongated cells, dark or densely packed chromatin, absent or mild nuclear atypia, inconspicuous nucleoli, and the absence of intranuclear pseudoinclusions. On the basis of these findings, the cytological features that can be of diagnostic help are (1) the presence of a hypercellular smear composed of papillary structures and dispersed single cells lacking necrosis; (2) the presence of cellular crowding and pseudostratified nuclei with dark chromatin without atypia, nucleoli, or mitosis; and (3) scarce/absent nuclear pseudoinclusions and predominantly scarce/absent nuclear grooves. These tumors show variable thyroglobulin expression, but their constant expression of TTF1 is helpful in diagnosing this variant [58]. TCV should be considered in the histological differential diagnosis. In contrast to TCV, CCV tumor cells typically lack light eosinophilic cytoplasm and delicate cell borders. The absence of easily identifiable intranuclear pseudo-inclusions and nuclear grooves would also favor CCV [58]. It is important to differentiate the encapsulated columnar cell variant from the cribriform-morular variant of PTC since the latter can be the first manifestation of familial adenomatous polyposis. Columnar cell variant usually lacks the squamous morules typical for the cribriform-morular variant and does not have nuclear expression for beta-catenin [54].

\section{Molecular Features}

Chen et al. [54] demonstrated that 33\% of their cases of CCV had the $B R A F^{\mathrm{V} 600 \mathrm{E}}$ mutation, a percentage somewhat similar to that expressed by the classic PTC, which supports the idea that the CCV are a variant of PTC.

\section{Solid Variant}

\section{Main Features}

SV is one of the rarest subtypes (3\% of all PTC) [59] and was described in 1985 by Carcangiu 
et al. [60]. It was initially linked to young age, $R E T / P T C 3$ fusions, and radiation exposure. After the Chernobyl accident, $37 \%$ of the subsequent PTC cases were SV [13]. However, SV has also been described in patients who have not been exposed to radiation [61]. Chang et al. [62] reviewed 14 cases of SV, none of whom had been exposed to radiation. The 12 women and 2 men had a mean age of 48.2 years. Guleria et al. [63] reported nine cases with a mean age of 43.9 years, five male and four female.

$\mathrm{SV}$ is associated with a higher risk of metastasis and a worse prognosis than classic PTC [64]. It is common for PTCs to have areas of solid and/or trabecular growth, which is more common for tumors in the pediatric age group $[1,65]$. However, the term "solid variant" should be used when all or nearly all of the tumor has a solid, trabecular, or nested (insular) appearance. The most frequent differential diagnosis is follicular carcinoma with a solid pattern [37] and poorly differentiated thyroid carcinoma. One-third of patients present with vascular invasion and extrathyroidal extension [66]. Chang et al. believe that the clinical characteristics of the SV are the same as those of the classic PTC in terms of frequency of lymph node metastases, distant metastases, and recurrences [62]. In contrast, Vuong et al. [67] found in their meta-analysis of 11 studies of 205 cases of SV that this is an aggressive variant with higher risk of tumor recurrence and mortality. Ohashi et al. [68] in their study with $27 \mathrm{SV}$ patients found that compared with classic PTC, SV was associated with larger tumor size, higher rates of lymphovascular invasion, lymph node metastases, extracapsular infiltration, higher recurrence rate, and shorter disease-free survival.

\section{Diagnosis}

\section{Histological Features}

One of the problems in attempting to diagnose SV is the lack of consensus as to what solid proportion of the cancer is necessary for a diagnosis of SV. Nikiforov and Gnepp [13] used 70\%, whereas Carcangiu et al. [60] and Ohashi et al. [69] require a 50\% solid component proportion. According to the latest WHO classification of endocrine tumors, all or nearly all of the tumor should be composed of a solid growth pattern [1]. It is very important to differentiate the solid variant from poorly differentiated thyroid carcinoma since the latter imparts a much poorer survival rate. Although they share a solid growth pattern, the solid variant exhibits nuclear features diagnostic of PTC and lacks the high mitotic rate and tumor necrosis found in poorly differentiated thyroid carcinoma. Guleria et al. [63] state that "the presence of solid fragments as the predominant architecture and total lack of true papillae in a cytology smear showing diffuse and well-developed nuclear features favor a diagnosis of SV". Another characteristic is the lack of necrosis and prominent mitotic activity [37] (Fig. 1c-e).

\section{Molecular Features}

The RET/PTC3 rearrangement is usually observed in this variant of PTC [65]. Trovisco et al. [70] detected a novel BRAF mutation in a case of $\mathrm{SV}$, a triplet deletion in $B R A F$ leading to the replacement of a valine and a lysine by a glutamate $\left(B R A F^{\mathrm{V} 600 \mathrm{E}+\mathrm{K} 601}\right)$.

\section{Hobnail Variant}

\section{Main Features}

$\mathrm{HV}$ is a rare variant of PTC described by Asioli et al. [25] in 2010 as a moderately differentiated PTC variant with aggressive behavior and significant mortality. However, previous reports from Japanese researchers indicated that PTC with this morphology was associated with increased risk of recurrence in thyroid cancer $[71,72]$. This variant is characterized by "hobnail" cells (i.e., apically located tumor nuclei bulging from the surface of the epithelium), micropapillary growth patterns, and a high nuclear/cytoplasmic ratio. In order for a tumor to be labeled as hobnail variant, the hobnail cells should comprise at least $30 \%$ of the neoplastic cells according to the most recent WHO classification of endocrine tumors [1]. Reviewing 2534 PTC from 1955 to 2004 at the Mayo Clinic, Asioli et al. found eight cases (six women and two men), with a mean age of 57.6 years 
and the most common initial symptom was a neck mass and cervical lymphadenopathy [25]. In a 2013 paper [73], the same authors retrospectively analyzed 24 cases of HV (including the eight cases previously described in 2010), with a mean age of 57.3 years ( 18 women and 6 men). Vascular invasion was detected in $70.8 \%$ of the cases and extrathyroidal extension in $58.3 \%$. The overall survival at 5 and 10 years was $69.1 \%$ and $64.1 \%$, respectively. The authors conclude that $\mathrm{HV}$ appears to be more aggressive than classic PTC, regardless of the proportion of hobnail/micropapillary features. In 2014, Lubitz et al. [74] analyzed 12 cases of HV (average age 54.1 years, nine female and three male), frequently finding extrathyroid extension (58.3\%), lymphovascular invasion (41.7\%), and lymph node metastasis (75\%). Amacher et al. [75] confirmed the more aggressive behavior of HV. Observing hobnail features more commonly in poorly differentiated thyroid carcinoma than in classic PTC, they suggested it may be a sign of higher-grade transformation. HV is associated not only with more aggressive behavior but also with RAI refractoriness, disease progression, and a higher mortality rate compared to classic PTC [76]. Morandi et al. [77] analyzed $18 \mathrm{HV}$ and only $33.3 \%$ of the cases were responsive to RAI therapy.

\section{Diagnosis}

\section{Histological Features}

A "hobnail pattern" is the term for describing cells with a high nuclear/cytoplasmic ratio and apically placed, occasionally grooved nuclei that produce a surface bulge, accounting for the term "hobnail" or "matchstick". Hobnail cells can vary in size and shape, from small lymphocytoid cells to larger cuboidal cells and even tall/columnar cells (Fig. 2e, f). The hobnail pattern is associated with the loss of cellular polarity and the loss of cohesiveness and suggests an epithelial-mesenchymal transition as a possible mechanism of metastasis [25, 78]. HVs are positive for thyroglobulin, TTF1, and epithelial membrane antigen (EMA). Overexpression of p53 protein by immunohistochemistry has been reported in more than $25 \%$ of the neoplastic cell nuclei in $77 \%$ of cases. $\beta$-catenin and E-cadherin stains show patchy lateral and/ or basolateral membrane positivity. HV also displays cytokeratin 7, cytokeratin 19, and HBME-1 as well as a mean Ki67 index of about $10 \%[73,78]$. The latter finding is consistent with the fact that HVs have often a high mitotic rate. Indeed, the presence of at least 3 mitoses/ 10 high power fields was found in $70 \%$ of cases in one study [79]. Recently, Wong et al. [79] have shown that classic PTCs can have cells with hobnail morphology in a significant portion of the tumor and still maintain a very indolent course. However, these classic PTCs with hobnail cells differ from the aggressive HVs by the lack of other aggressive histologic features such as high mitotic rate and extrathyroid extension. One therefore could question whether the aggressive behavior of the HV is due to its high mitotic rate or extensive invasion rather than the presence of the typical hobnail cells.

\section{Molecular Features}

According to the first description by Asioli et al. [25], BRAF mutations were detected in $57.1 \%$ of cases. Lubitz et al. [74] found that the mean percentage of $B R A F^{\mathrm{V} 600 \mathrm{E}}$ alleles was $25.3 \%$. They also found that $80 \%$ of the tumors were positive for $B R A F^{\mathrm{V} 600 \mathrm{E}}$ while $20 \%$ harbored RET/PTC1 fusions.

Morandi et al. [77] investigated the molecular data of HV and found that BRAF and TP53 mutations were the most common genetic alterations in primary $\mathrm{HV}(72.2 \%$ and $55.6 \%$, respectively), followed by hTERT (44.4\%), PIK3CA (27.8\%), CTNNB1 (16.7\%), EGFR (11.1\%), AKT1 (5.5\%), and NOTCH1 (5.5\%). The mutational pattern remains unaltered in the primary tumor and in metastasis. Univariate Cox regression analyses indicated a significantly increased mortality risk in patients with $B R A F$ mutation. Further increase in mortality was seen in BRAF mutation associated with TP53 and/or PIK3CA mutations.

\section{TREATMENT}

According to the ATA recommendations [3], treatment of all of these histological variants is 
basically the same: Lobectomy for small unifocal intrathyroidal tumors and total thyroidectomy, with therapeutic neck dissection if nodes are involved or prophylactic central compartment node dissection for $\mathrm{T} 3$ and $\mathrm{T} 4$ tumors. Following the total thyroidectomy, the need for RAI therapy should be considered. Wang et al. [55] suggested that because of the poorer prognosis of CCV, radical approaches should be considered. It is important to identify the indolent cases as they have a better outcome with a low incidence of recurrences or metastasis $[52,53,56]$. For TCV one must take into account that approximately $20 \%$ are refractory to RAI. Gunalp et al. [35] found that TCV histology implies a higher incidence of extrathyroidal and lymphovascular invasion, and distant metastasis. These factors are responsible for the higher recurrence rates and worse prognosis of TCV compared with classic PTC. They also recommend aggressive treatment especially in early stages of the disease. As aggressive recurrent thyroid tumors are frequently nonRAI-avid and $\left[{ }^{18} \mathrm{~F}\right]$ fluorodeoxyglucose (FDG)positron emission tomography (PET)-positive, Rivera et al. [80] examined these carcinomas microscopically. They found that $20 \%$ of the cases were TCV with extensive extrathyroidal extension into adjacent fibroadipose tissue and/ or skeletal muscle. Since most pathologists nowadays are familiar with TCV PTC features and sample generously the thyroid gland, it is not uncommon to find small even subcentimeter TCV PTC confined to the thyroid without vascular invasion. Because we do not know if stage for stage TCV PTC is more aggressive than classic PTC, aggressive treatment of such incidental small TCV PTC should be questioned in our opinion and treatment decisions made in a multidisciplinary fashion. In addition it is not clear how to treat patients with PTC showing a tall cell component that does not reach the "official" diagnostic percentage cutoff. In relation to CCV, it is important to identify the indolent encapsulated cases as they have a better outcome with a low incidence of recurrences or metastasis $[52,53,56]$. With respect to SV, some authors suggest that treatment and follow-up should be strict since they have a greater rate of vascular invasion and recurrence than classic PTC [67]. Early diagnosis and close surveillance are essential in the management of patients with HV according to Asioli et al. [25]. In the future these tumors may be treated by targeting different molecular pathways [78].

One aspect that must be taken into account is that DSV, which is more prevalent in children and young patients, particularly tends to be iodine-avid and even patients with distant metastases have a good prognosis [81, 82]. On the contrary, the other variants, which affect mostly older patients, with locally invasive or locally recurrent disease, are RAI refractory and have a poor prognosis.

Reviewing the literature and the biological behavior of all of the variants of PTC mentioned above, it becomes evident that the ones which are aggressive and have a poorer outcome are tumors which are higher staged, have gross extrathyroid extension, or those who present with nodal or distant metastases. In general, the prognosis remains excellent and similar to PTC, for small (T1-2) tumors, which are intrathyroidal at presentation. Thus, the treatment decision is based on the extent of tumor at presentation rather than the histological variant of PTC.

\section{DISCUSSION}

Classic PTC is usually an indolent disease with an associated 10-year survival of over 95\% [2]. This manuscript describes the variants of PTC with an aggressive behavior, placing them on the spectrum between a low-grade PTC and poorly differentiated/anaplastic thyroid carcinoma. They appear to have higher rates of metastases, recurrence, resistance to RAI therapy, and compromised survival [18]. However, such aggressive behavior is usually associated with larger tumors presenting with extrathyroid extension or nodal or distant metastases. The rarity of these tumors and the poor understanding of their biology may lead to inadequate treatment. For this reason, we conducted this review with the purpose of updating the thyroid cancer clinician on the histological characteristics of the aggressive variants of PTC and the treatment implications for these 
patients. An early and correct diagnosis can lead to appropriate treatment and improved prognosis for these patients.

Unfortunately, the diagnosis can be confirmed with an FNA in very rare cases; however, those cytology reports show be interpreted with caution as an FNA specimen might not be representative of the entire lesion and some variants need to reach defined tumor percentage thresholds. In almost all instances the diagnosis of aggressive variants of PTC is diagnosed after surgery. Therefore, surgical pathologists should be cognizant of the effect of these variants in the risk stratification of patients with PTC.

There is no doubt that each of these aggressive variants of PTC has worse outcome than classic PTC as a whole (e.g., all TCV cases vs. all patients with classic PTC). The important question is the independent prognostic value of these variants when stratified by stage or other aggressive histologic features such as mitotic rate and degree of invasion. This question has been answered for the rarest aggressive variant which is the CCV. The study by Wenig et al. [52] clearly shows that the encapsulated form of $\mathrm{CCV}$ is an indolent disease while the widely infiltrative CCV is very aggressive. So, it is encapsulation rather than the columnar cells (the latter being the defining feature of CCV) that drives outcome in CCV PTC. Unfortunately, we do not have a definitive answer for the other aggressive variant especially the most common one which is TCV PTC. However, a recent study by Limberg et al. [83] analyzed data from the National Cancer Database and their findings showed that in the absence of invasive features, TCV, CCV, and DSV have similar overall survival to that of classic PTC; and some authors have shown that the presence of tall cells is not an independent prognostic feature [30].

Given this uncertainty as to the independent prognostic value of these aggressive variants of PTC, it is important to rely on established prognostic features (such as large size, gross extrathyroid extension, extensive vascular invasion) when deciding on the extent of surgery or the need for adjuvant therapy. For example, an 8-mm TCV PTC confined to the thyroid may not need more than a simple lobectomy while TCV PTC with gross extrathyroid extension in the trachea will need total thyroidectomy with or without tracheal resection depending on the extent of the tumor with RAI therapy. The fundamental surgical principle of "gross total excision", with an R0 resection when feasible must remain the gold standard for planning surgery for thyroid cancer. On the other hand, with the identification of new molecular targets and development of new therapeutic agents, these tumors would be excellent targets to explore the efficacy of new systemic therapies and improvement in outcomes through clinical trials.

\section{CONCLUSIONS}

The correct diagnosis of the most aggressive variants of PTC can represent a diagnostic challenge even for expert histopathologists. Each aggressive variant imparts a worse outcome than classic PTC. At the present time, we do not know the independent prognostic value of the morphology of aggressive PTC variants by itself. In view of this uncertainty, the extent of the surgical treatment and adjuvant therapy required is an individualized decision made by experienced clinicians guided by the extent of tumor at initial presentation. Future well-controlled outcome studies are needed to assess the independent prognostic value of these variants. Novel advances at the molecular level may open the way for future targeted therapies that may help improve the survival of these patients.

\section{ACKNOWLEDGEMENTS}

Funding. No funding or sponsorship was received for this study or publication of this article.

Authorship. All named authors meet the International Committee of Medical Journal Editors (ICMJE) criteria for authorship for this article, take responsibility for the integrity of the work as a whole, and have given their approval for this version to be published. 
Disclosures. Alfio Ferlito and Alessandra Rinaldo are on the Editorial Board of Advances in Therapy but have nothing else relevant to disclose. All remaining authors Andrés Coca-Pelaz, Jatin P. Shah, Juan C. Hernandez-Prera, Ronald A. Ghossein, Juan P. Rodrigo, Dana M. Hartl, Kerry D. Olsen, Ashok R. Shaha, Mark Zafereo, Carlos Suarez, Iain J. Nixon, Gregory W. Randolph, Antti A. Mäkitie, Luiz P. Kowalski, Vincent Vander Poorten, Alvaro Sanabria, Orlando Guntinas-Lichius, Ricard Simo, Peter Zbären, Peter Angelos, Avi Khafif have nothing to disclose.

Compliance with Ethics Guidelines. This article is based on previously conducted studies and does not contain any studies with human participants or animals performed by any of the authors.

Open Access. This article is licensed under a Creative Commons Attribution-NonCommercial 4.0 International License, which permits any non-commercial use, sharing, adaptation, distribution and reproduction in any medium or format, as long as you give appropriate credit to the original author(s) and the source, provide a link to the Creative Commons licence, and indicate if changes were made. The images or other third party material in this article are included in the article's Creative Commons licence, unless indicated otherwise in a credit line to the material. If material is not included in the article's Creative Commons licence and your intended use is not permitted by statutory regulation or exceeds the permitted use, you will need to obtain permission directly from the copyright holder. To view a copy of this licence, visit http://creativecommons.org/licenses/by$\mathrm{nc} / 4.0 /$.

\section{REFERENCES}

1. Lloyd R, Osamura R, Klöppel G, Rosai J. WHO classification of tumours of endocrine organs. 4th ed. Lyon: International Agency for Research on Cancer; 2017.
2. Clark OH. Thyroid cancer and lymph node metastases. J Surg Oncol. 2011;103:615-8.

3. Haugen BR, Alexander EK, Bible KC, et al. 2015 American Thyroid Association Management Guidelines for adult patients with thyroid nodules and differentiated thyroid cancer: the American Thyroid Association Guidelines task force on thyroid nodules and differentiated thyroid cancer. Thyroid. 2016;26:1-133.

4. Lam AK-Y, Lo C-Y, Lam KS-L. Papillary carcinoma of thyroid: a 30-year clinicopathological review of the histological variants. Endocr Pathol. 2005;16: 323-30.

5. Carling T, Ocal IT, Udelsman R. Special variants of differentiated thyroid cancer: does it alter the extent of surgery versus well-differentiated thyroid cancer? World J Surg. 2007;31:916-23.

6. Vickery AL, Carcangiu ML, Johannessen JV, Sobrinho-Simoes M. Papillary carcinoma. Semin Diagn Pathol. 1985;2:90-100.

7. Chow S-M, Chan JKC, Law SCK, et al. Diffuse sclerosing variant of papillary thyroid carcinomaclinical features and outcome. Eur J Surg Oncol. 2003;29:446-9.

8. Pillai S, Gopalan V, Smith RA, Lam AK-Y. Diffuse sclerosing variant of papillary thyroid carcinomaan update of its clinicopathological features and molecular biology. Crit Rev Oncol Hematol. 2015;94:64-73.

9. Lam AKY, Lo CY. Diffuse sclerosing variant of papillary carcinoma of the thyroid: a 35-year comparative study at a single institution. Ann Surg Oncol. 2006;13:176-81.

10. Falvo L, Giacomelli L, D'Andrea V, Marzullo A, Guerriero G, de Antoni E. Prognostic importance of sclerosing variant in papillary thyroid carcinoma. Am Surg. 2006;72:438-44.

11. Kazaure HS, Roman SA, Sosa JA. Aggressive variants of papillary thyroid cancer: incidence, characteristics and predictors of survival among 43,738 patients. Ann Surg Oncol. 2012;19:1874-80.

12. Fridman MV, Savva NN, Krasko OV, et al. Clinical and pathologic features of "sporadic" papillary thyroid carcinoma registered in the years 2005 to 2008 in children and adolescents of Belarus. Thyroid. 2012;22:1016-24.

13. Nikiforov Y, Gnepp DR. Pediatric thyroid cancer after the Chernobyl disaster. Pathomorphologic study of 84 cases (1991-1992) from the Republic of Belarus. Cancer. 1994;74:748-66. 
14. Regalbuto C, Malandrino P, Tumminia A, Le Moli $\mathrm{R}$, Vigneri R, Pezzino V. A diffuse sclerosing variant of papillary thyroid carcinoma: clinical and pathologic features and outcomes of 34 consecutive cases. Thyroid. 2011;21:383-9.

15. Vuong HG, Kondo T, Pham TQ, et al. Prognostic significance of diffuse sclerosing variant papillary thyroid carcinoma: a systematic review and metaanalysis. Eur J Endocrinol. 2017;176:433-41.

16. Takagi N, Hirokawa M, Nobuoka Y, Higuchi M, Kuma S, Miyauchi A. Diffuse sclerosing variant of papillary thyroid carcinoma: a study of fine needle aspiration cytology in 20 patients. Cytopathology. 2014;25:199-204.

17. Koo JS, Shin E, Hong SW. Immunohistochemical characteristics of diffuse sclerosing variant of papillary carcinoma: comparison with conventional papillary carcinoma. APMIS. 2010;118:744-52.

18. Silver CE, Owen RP, Rodrigo JP, Rinaldo A, Devaney $\mathrm{KO}$, Ferlito A. Aggressive variants of papillary thyroid carcinoma. Head Neck. 2011;33:1052-9.

19. Sheu S-Y, Schwertheim S, Worm K, Grabellus F, Schmid KW. Diffuse sclerosing variant of papillary thyroid carcinoma: lack of BRAF mutation but occurrence of RET/PTC rearrangements. Mod Pathol. 2007;20:779-87.

20. Joung JY, Kim TH, Jeong DJ, et al. Diffuse sclerosing variant of papillary thyroid carcinoma: major genetic alterations and prognostic implications. Histopathology. 2016;69:45-53.

21. Smith RA, Salajegheh A, Weinstein S, Nassiri M, Lam AK-Y. Correlation between BRAF mutation and the clinicopathological parameters in papillary thyroid carcinoma with particular reference to follicular variant. Hum Pathol. 2011;42:500-6.

22. Lin X, Finkelstein SD, Zhu B, Silverman JF. Molecular analysis of multifocal papillary thyroid carcinoma. J Mol Endocrinol. 2008;41:195-203.

23. Lee J-H, Lee ES, Kim Y-S, Won NH, Chae Y-S. BRAF mutation and AKAP9 expression in sporadic papillary thyroid carcinomas. Pathology. 2006;38:201-4.

24. Lim JY, Hong SW, Lee YS, et al. Clinicopathologic implications of the BRAF(V600E) mutation in papillary thyroid cancer: a subgroup analysis of 3130 cases in a single center. Thyroid. 2013;23:1423-30.

25. Asioli S, Erickson LA, Sebo TJ, et al. Papillary thyroid carcinoma with prominent hobnail features: a new aggressive variant of moderately differentiated papillary carcinoma. A clinicopathologic, immunohistochemical, and molecular study of eight cases. Am J Surg Pathol. 2010;34:44-52.
26. Koperek O, Kornauth C, Capper D, et al. Immunohistochemical detection of the BRAF V600E-mutated protein in papillary thyroid carcinoma. Am J Surg Pathol. 2012;36:844-50.

27. Sheu S-Y, Grabellus F, Schwertheim S, Handke S, Worm K, Schmid KW. Lack of correlation between BRAF V600E mutational status and the expression profile of a distinct set of miRNAs in papillary thyroid carcinoma. Horm Metab Res. 2009;41:482-7.

28. Hawk WA, Hazard JB. The many appearances of papillary carcinoma of the thyroid. Cleve Clin Q. 1976;43:207-15.

29. Crile G, Hazard JB, Dinsmore RS. Carcinoma of the thyroid gland, with special reference to a clinicopathologic classification. J Clin Endocrinol Metab. 1948;8:762-5.

30. Ganly I, Ibrahimpasic T, Rivera M, et al. Prognostic implications of papillary thyroid carcinoma with tall-cell features. Thyroid. 2014;24:662-70.

31. Beninato T, Scognamiglio T, Kleiman DA, et al. Ten percent tall cells confer the aggressive features of the tall cell variant of papillary thyroid carcinoma. Surgery. 2013;154:1331-6.

32. Oh WJ, Lee YS, Cho U, et al. Classic papillary thyroid carcinoma with tall cell features and tall cell variant have similar clinicopathologic features. Korean J Pathol. 2014;48:201-8.

33. LiVolsi VA. Papillary carcinoma tall cell variant (TCV): a review. Endocr Pathol. 2010;21:12-5.

34. Wang X, Cheng W, Liu C, Li J. Tall cell variant of papillary thyroid carcinoma: current evidence on clinicopathologic features and molecular biology. Oncotarget. 2016;7:40792-9.

35. Gunalp B, Okuyucu K, Ince S, Ayan A, Alagoz E. Impact of tall cell variant histology on predicting relapse and changing the management of papillary thyroid carcinoma patients. Hell J Nucl Med. 2017;20:122-7.

36. Morris LGT, Shaha AR, Tuttle RM, Sikora AG, Ganly I. Tall-cell variant of papillary thyroid carcinoma: a matched-pair analysis of survival. Thyroid. 2010;20: 153-8.

37. Nath MC, Erickson LA. Aggressive variants of papillary thyroid carcinoma: hobnail, tall cell, columnar, and solid. Adv Anat Pathol. 2018;25:172-9.

38. Russo M, Malandrino P, Moleti M, et al. Tall cell and diffuse sclerosing variants of papillary thyroid cancer: outcome and predicting value of risk stratification methods. J Endocrinol Invest. 2017;40: $1235-41$. 
39. Vuong HG, Long NP, Anh NH, et al. Papillary thyroid carcinoma with tall cell features is as aggressive as tall cell variant: a meta-analysis. Endocr Connect. 2018;7:R286-93.

40. Bongers PJ, Kluijfhout WP, Verzijl R, et al. Papillary thyroid cancers with focal tall cell change are as aggressive as tall cell variants and should not be considered as low-risk disease. Ann Surg Oncol. 2019;26:2533-9.

41. Wong KS, Higgins SE, Marqusee E, Nehs MA, Angell $\mathrm{T}$, Barletta JA. Tall cell variant of papillary thyroid carcinoma: impact of change in WHO definition and molecular analysis. Endocr Pathol. 2019;30: 43-8.

42. Hernandez-Prera JC, Machado RA, Asa SL, et al. Pathologic reporting of tall-cell variant of papillary thyroid cancer: have we reached a consensus? Thyroid. 2017;27:1498-504.

43. Solomon A, Gupta PK, LiVolsi VA, Baloch ZW. Distinguishing tall cell variant of papillary thyroid carcinoma from usual variant of papillary thyroid carcinoma in cytologic specimens. Diagn Cytopathol. 2002;27:143-8.

44. Das DK, Mallik MK, Sharma P, et al. Papillary thyroid carcinoma and its variants in fine needle aspiration smears. A cytomorphologic study with special reference to tall cell variant. Acta Cytol. 2004;48:325-36.

45. Erler P, Keutgen XM, Crowley MJ, et al. Dicer expression and microRNA dysregulation associate with aggressive features in thyroid cancer. Surgery. 2014;156:1342-50 (discussion 1350).

46. Basolo F, Giannini R, Monaco C, et al. Potent mitogenicity of the RET/PTC3 oncogene correlates with its prevalence in tall-cell variant of papillary thyroid carcinoma. Am J Pathol. 2002;160:247-54.

47. Cancer Genome Atlas Research Network. Integrated genomic characterization of papillary thyroid carcinoma. Cell. 2014;159:676-90.

48. Sywak M, Pasieka JL, Ogilvie T. A review of thyroid cancer with intermediate differentiation. J Surg Oncol. 2004;86:44-54.

49. Gaertner EM, Davidson M, Wenig BM. The columnar cell variant of thyroid papillary carcinoma. Case report and discussion of an unusually aggressive thyroid papillary carcinoma. Am J Surg Pathol. 1995;19:940-7.

50. Sujoy V, Pinto A, Nosé V. Columnar cell variant of papillary thyroid carcinoma: a study of 10 cases with emphasis on CDX2 expression. Thyroid. 2013;23:714-9.
51. Enriquez ML, Baloch ZW, Montone KT, Zhang PJ, LiVolsi VA. CDX2 expression in columnar cell variant of papillary thyroid carcinoma. Am J Clin Pathol. 2012;137:722-6.

52. Wenig BM, Thompson LD, Adair CF, Shmookler B, Heffess CS. Thyroid papillary carcinoma of columnar cell type: a clinicopathologic study of 16 cases. Cancer. 1998;82:740-53.

53. Cho J, Shin JH, Hahn SY, Oh YL. Columnar cell variant of papillary thyroid carcinoma: ultrasonographic and clinical differentiation between the indolent and aggressive types. Korean J Radiol. 2018;19:10-5.

54. Chen J-H, Faquin WC, Lloyd RV, Nosé V. Clinicopathological and molecular characterization of nine cases of columnar cell variant of papillary thyroid carcinoma. Mod Pathol. 2011;24:739-49.

55. Wang S, Xiong Y, Zhao Q, Song H, Yi P, Liu C. Columnar cell papillary thyroid carcinoma prognosis: findings from the SEER database using propensity score matching analysis. Am J Transl Res. 2019;11:6262-70.

56. Jiang C, Cheng T, Zheng X, et al. Clinical behaviors of rare variants of papillary thyroid carcinoma are associated with survival: a population-level analysis. Cancer Manag Res. 2018;10:465-72.

57. Bongiovanni M, Mermod M, Canberk S, et al. Columnar cell variant of papillary thyroid carcinoma: cytomorphological characteristics of 11 cases with histological correlation and literature review. Cancer Cytopathol. 2017;125:389-97.

58. Rottuntikarn W, Wangsiricharoen S, Rangdaeng S. Cytomorphology and immunocytochemistry of columnar cell variant of papillary thyroid carcinoma. Cytopathology. 2017;28:338-41.

59. Sak SD. Variants of papillary thyroid carcinoma: multiple faces of a familiar tumor. Turk Patol Derg. 2015;31(Suppl 1):34-47.

60. Carcangiu ML, Zampi G, Pupi A, Castagnoli A, Rosai J. Papillary carcinoma of the thyroid. A clinicopathologic study of 241 cases treated at the University of Florence, Italy. Cancer. 1985;55: 805-28.

61. Damle N, Ramya S, Bal C, Durgapal P. Solid variant of papillary carcinoma thyroid in a child with no history of radiation exposure. Indian J Nucl Med. 2011;26:196-8.

62. Chang H, Kim SM, Chun KW, et al. Clinicopathologic features of solid variant papillary thyroid cancer. ANZ J Surg. 2014;84:380-2. 
63. Guleria P, Phulware R, Agarwal S, et al. Cytopathology of solid variant of papillary thyroid carcinoma: differential diagnoses with other thyroid tumors. Acta Cytol. 2018;62:371-9.

64. Sebastian SO, Gonzalez JM, Paricio PP, et al. Papillary thyroid carcinoma: prognostic index for survival including the histological variety. Arch Surg. 2000;135:272-7.

65. Vander Poorten V, Hens G, Delaere P. Thyroid cancer in children and adolescents. Curr Opin Otolaryngol Head Neck Surg. 2013;21:135-42.

66. Lloyd RV, Buehler D, Khanafshar E. Papillary thyroid carcinoma variants. Head Neck Pathol. 2011;5: 51-6.

67. Vuong HG, Odate T, Duong UNP, et al. Prognostic importance of solid variant papillary thyroid carcinoma: a systematic review and meta-analysis. Head Neck. 2018;40:1588-97.

68. Ohashi R, Kawahara K, Namimatsu S, et al. Clinicopathological significance of a solid component in papillary thyroid carcinoma. Histopathology. 2017;70:775-81.

69. Ohashi R, Murase Y, Matsubara M, et al. Fine needle aspiration cytology of the papillary thyroid carcinoma with a solid component: a cytological and clinical correlation. Diagn Cytopathol. 2017;45: 391-8.

70. Trovisco V, Soares P, Soares R, Magalhães J, SáCouto P, Sobrinho-Simões M. A new BRAF gene mutation detected in a case of a solid variant of papillary thyroid carcinoma. Hum Pathol. 2005;36: 694-7.

71. Kakudo K, Tang W, Ito Y, Mori I, Nakamura Y, Miyauchi A. Papillary carcinoma of the thyroid in Japan: subclassification of common type and identification of low risk group. J Clin Pathol. 2004;57: 1041-6.

72. Motosugi U, Murata S-I, Nagata K, Yasuda M, Shimizu M. Thyroid papillary carcinoma with micropapillary and hobnail growth pattern: a histological variant with intermediate malignancy? Thyroid. 2009;19:535-7.

73. Asioli S, Erickson LA, Righi A, Lloyd RV. Papillary thyroid carcinoma with hobnail features: histopathologic criteria to predict aggressive behavior. Hum Pathol. 2013;44:320-8.
74. Lubitz CC, Economopoulos KP, Pawlak AC, et al. Hobnail variant of papillary thyroid carcinoma: an institutional case series and molecular profile. Thyroid. 2014;24:958-65.

75. Amacher AM, Goyal B, Lewis JS, El-Mofty SK, Chernock RD. Prevalence of a hobnail pattern in papillary, poorly differentiated, and anaplastic thyroid carcinoma: a possible manifestation of high-grade transformation. Am J Surg Pathol. 2015;39:260-5.

76. Asioli S, Maletta F, Pagni F, et al. Cytomorphologic and molecular features of hobnail variant of papillary thyroid carcinoma: case series and literature review. Diagn Cytopathol. 2014;42:78-84.

77. Morandi L, Righi A, Maletta F, et al. Somatic mutation profiling of hobnail variant of papillary thyroid carcinoma. Endocr Relat Cancer. 2017;24: 107-17.

78. Ambrosi F, Righi A, Ricci C, Erickson LA, Lloyd RV, Asioli S. Hobnail variant of papillary thyroid carcinoma: a literature review. Endocr Pathol. 2017;28: 293-301.

79. Wong KS, Chen TY, Higgins SE, et al. A potential diagnostic pitfall for hobnail variant of papillary thyroid carcinoma. Histopathology. 2019;76: 707-13.

80. Rivera M, Ghossein RA, Schoder H, Gomez D, Larson SM, Tuttle RM. Histopathologic characterization of radioactive iodine-refractory fluorodeoxyglucose-positron emission tomography-positive thyroid carcinoma. Cancer. 2008;113: 48-56.

81. Malandrino P, Russo M, Regalbuto C, et al. Outcome of the diffuse sclerosing variant of papillary thyroid cancer: a meta-analysis. Thyroid. 2016;26: 1285-92.

82. Yamashita $H$, Noguchi $S$, Takahashi $H$, et al. The diffuse sclerosing variant of papillary thyroid carcinoma is not an aggressive subtype of papillary carcinoma. J Thyroid Disord Ther. 2014;3:163.

83. Limberg J, Ullmann TM, Stefanova D, et al. Does aggressive variant histology without invasive features predict overall survival in papillary thyroid cancer? A National Cancer Database Analysis. Ann Surg. 2019. https://doi.org/10.1097/SLA. 0000000000003632 . 